\title{
COVID - 19 - Threat to Dentistry - How to Overcome?
}

\author{
Hema Kanathila ${ }^{1}$, Ashwin Pangi ${ }^{2}$, Bharathi ${ }^{3}$ \\ ${ }^{1}$ Department of Prosthodontics, KAHER'S, KLE VK Institute of Dental Sciences, Belagavi, Karnataka, \\ India. ${ }^{2}$ Department of Prosthodontics, Belagavi, Karnataka, India. ${ }^{3}$ Department of Periodontics, \\ Sharavati Dental College, Shivamogga, Karnataka, India.
}

\section{ABSTRACT}

\section{BACKGROUND}

The latest highly contagious disease Covid - 19 has created a havoc all over the world pausing everyone's normal life and has become a major public health concern. This novel corona virus with human to human transmission has put the world to halt and has become a major concern for all healthcare professionals. Patients infected with COVID - 19 present with dry cough, sore throat, fever and more severe cases exhibit shortness of breath. Loss of smell and loss of taste are other symptoms observed in infected patients. The routes of transmission of Sars - CoV - 2 are direct contact and airborne transmission. Infection by direct contact occurs through close contact of surfaces that are contaminated and subsequent touching of nose, mouth or eyes. Dental practitioners are at a higher risk because of its potential transmission via saliva, water droplets, and aerosols generated during most of the dental clinical procedures. Because of its highly contagious nature, it possesses serious lifethreatening problems for both patient and the dentist. Many patients with dental pain and infections approach dental professionals at this time of crisis. Hence, dental professionals must be ready to provide emergency dental services by taking precautionary and safety measures. This COVID - 19 pandemic has posed economic and social difficulties for all including dental professionals. Therefore, instead of restricting dental procedures, it is better to think of tackling the risk of infection by following all the safety procedures and by orienting the dental treatment by taking a more preventive, conservative and less invasive approach. Infection control and management becomes very important in treating patients in the coming months. Hence, use of personal protective equipment, hand hygiene, use of mouth rinses during the procedure, rubber dam isolation, and disinfection of the dental clinic help in reducing the risk of infection to a great extent. This article gives a view of symptoms, routes of transmission, and safety measures to be considered, to overcome the fear of dental practice during this time of high risk and in the coming future.
Corresponding Author: Dr. Hema Kanathila. KAHER'S, KLE VK Institute of Dental Sciences, Belagavi, Karnataka, India. E-mail: hemak_19@yahoo.com

DOI: $10.14260 / j e m d s / 2020 / 596$

How to Cite This Article: Kanathila H, Pangi A, Bharathi. COVID - 19 threat to dentistry - how to overcome? J Evolution Med Dent Sci 2020;9(37):27462750, DOI: $10.14260 /$ jemds/2020/596

Submission 28-05-2020,

Peer Review 07-08-2020,

Acceptance 13-08-2020,

Published 14-09-2020.

Copyright (C) 2020 JEMDS. This is an open access article distributed under Creative Commons Attribution License [Attribution 4.0 International (CC BY 4.0)] 


\section{BACKGROUND}

The outbreak of coronavirus disease (Covid - 19) which started in Wuhan, Hubei (China), ${ }^{1,2}$ became a serious health crisis throughout the world, and has become a public health emergency, changing the lives of millions of people and even leading to tragic consequences. ${ }^{3}$ An individual with Covid 19, likely infects his primary contacts and those spreading to others creating secondary contacts when in direct and close proximity. It is contagious via contact with droplets and contaminated surfaces. It gets into the body through mucosal surfaces of eyes, nose and oral cavity. Hence it is of utmost importance to avoid individual to individual close contact (social or physical distancing), frequent use of sanitizers or hand washing and disinfection of public and private places, which helps in minimising spread of the novel corona virus.

Individuals can be asymptomatic carriers with no detectable manifestations or symptomatic with mild to moderate symptoms and some present with severe viral pneumonia presenting as myalgia, fever, dry cough, shortness of breath ${ }^{2,4}$ and kidney failure and even death as a final consequence. All the healthcare professionals are at a great risk as they are immediately involved in the national emergency and working hard on the cases. As Covid 19 was recently identified in patient's saliva, Dental professionals are considered to be even more at a higher risk due to direct contact with saliva, water droplets and aerosols which makes the spread easy as they are susceptible to catching and transferring this infectious virus to the assistants as well as other dental patients. The origin of droplets can be either nasopharyngeal or or pharyngeal, normally associated with saliva. Dental practitioners have been suggested to take several personal protective measures and avoid or minimize clinical procedures that can produce droplets or aerosols. Hence self -protection, infection control and management take the first place in order to avoid the risk of this novel coronavirus spread.

\section{Corona Virus}

The Covid 19 is different from SARS - CoV and MERS - CoV which caused severe respiratory diseases in 2002 and 2012 respectively. This novel corona virus which belongs to a family of single stranded RNA viruses called Corona viridae.5,6,7 Out of the 4 genera of coronavirus ie, $\alpha-\mathrm{CoV}, \beta-\mathrm{CoV}, \gamma-\mathrm{CoV}$, and $\delta$ $\mathrm{CoV}, 8,9$ Covid 19 belongs to $\beta-\mathrm{CoV}$, which mainly affect the respiratory, gastrointestinal and central nervous system of humans and mammals. ${ }^{10,11,12}$ Researchers investigated on the host of corona virus and suggested Rhinolophus affinis bat may be the natural host ${ }^{13}$ and pangolins may be intermediate host of covid $19 .{ }^{14}$ Corona virus got its name from crown like spikes on the surface of the virus. ${ }^{15}$ Hence, Covid 19 owned the coronavirus structure with spike protein in the membrane envelope. ${ }^{16}$ It also showed other nucleoproteins, polyproteins, membrane proteins and accessory proteins. ${ }^{17}$

\section{Symptoms of Covid 19}

Patients with Covid 19 can show mild, moderate or severe symptoms and some being asymptomatic can be the carriers of Covid 19. Covid 19 patient with clinical symptoms may exhibit fever, myalgia and dry cough. Along with these symptoms, nausea, diarrhoea, decreased sense of smell and abnormal taste sensation has been recorded.18 Severe forms causing pneumonia, respiratory distress and ultimately death. Around $80 \%$ patients showing milder symptoms which include flu like symptoms might have led to the spread of this infectious disease to more number of people thus increasing the count of getting infected with corona virus. ${ }^{19}$ Even though it has affected people of all ages, people with underlying diseases such as diabetes, hypertension, cardiovascular disease are at a higher risk of developing coronavirus disease.

\section{Transmission Routes in Dental Practice}

As dentistry involves close proximity to patient's face and oral cavity, and most of the dental procedures involve production of aerosols, dental practitioners are at a higher risk of getting and spreading the virus. It is a known fact of person to person transmission of coronavirus, it can be via respiratory droplets, saliva of patients with Covid 19 or aerosols creating more risk to dental practitioners. In dental practice not just the dental professional gets exposed, but other assistants in the clinical area are exposed frequently with aerosols that are produced during most of the dental procedures.5,20 For most of the dental clinical treatments, the standard protective protocol followed may not be sufficient to protect against coronavirus, especially when patients are just carriers or are asymptomatic or are in incubation period or if they do not provide a proper medical or travel history. In dental practice usually the novel coronavirus Covid - 19 can be spread by airborne route, direct contact, or through the contaminated surfaces. ${ }^{5}$

\section{Airborne Route of Transmission}

Many researchers have shown that most of the dental procedures generate aerosols and droplets contaminated with virus. To et al. confirmed the presence of live viruses in the saliva of infected individuals by viral culture method.21,22 During scaling procedures, tooth preparation, difficult extractions requiring bone cutting, restorations require aerotors and it is quite impossible to avoid the generation of aerosols and micro droplets combined with saliva or blood. These micro droplets and aerosols stay in air for a long time and later can settle on to hard surfaces and as well as enter the human respiratory tract if masks are not worn by dentists or attendants or assistants, making it very clear about the spread of Covid 19 from infected persons in dental clinics via airborne route.

\section{Contact Route of Transmission}

$\mathrm{CoV}$ can be transmitted directly from person to person by respiratory droplets, emerging evidence has shown that it may also be transmitted through contact and fomites. $5,21,23$ Contact route of transmission can be either direct contact or indirect contact. Dental practitioners are always in direct or indirect contact with human fluids like saliva or blood, dental materials used on patients, and contaminated dental instruments or even the surfaces in the clinic touched by patients. Hence all this can make an easy possible way for the transmission of viruses. 


\section{Contaminated Surface Route of Transmission}

Studies on Human coronaviruses such as SARS - CoV, Middle East Respiratory Syndrome coronavirus (MERS - CoV), or endemic human coronaviruses (HCoV) have shown that contaminated surfaces frequently contacted in hospitals are a potential source of coronavirus transmission. Coronaviruses can remain active on surfaces like glass, plastic or metal for up to a couple of days and it was shown that $\mathrm{HCoV}$ remains infectious from $2 \mathrm{~h}$ up to 9 days at room temperature and exists better at $50 \%$ compared with $30 \%$ relative humidity. ${ }^{24,25}$ In dental clinics, a Covid 19 patient's salivary / respiratory droplets and aerosols from infected patients can easily contaminate the whole surface.

With these risks of transmissions in mind, all the dental clinics all around the world have paused their routine dental practices. Dental practitioners have limited their services only to those patients who require emergency treatment like acute pulpitis, symptomatic hard and soft tissue lesions, fractured prostheses and investigations required for some lesions, thereby fulfilling their responsibilities, ${ }^{4}$ some are even managed with telephonic consultations. Now these routes of transmissions can be decreased to a lot extent by keeping a dry, clean clinic environment, thorough history taking, by using Personal Protective Equipment's (PPE) and following a strict infection control and management.

\section{COVID 19 in Dental Clinics - How to Overcome the Risk?}

As all the dental professionals are aware of the spread of Covid 19 , it becomes a common question in everyone's mind that how to overcome this risk and manage their normal patients and unaware Covid 19 patients. So first and foremost the dental practitioners should know what all extra - protective measures one has to follow in and out of the dental clinic. The dental practitioner will have to follow those now at the time of this outbreak as well as for a few months later after the Covid 19 till the fear of its spread completely gets cleared off.

Dental practitioners should know how to manage normal patients as well as an unaware Covid 19 patient, hence considering the spread taking all precautionary and self protective measures becomes very crucial. According to the guidelines, dentists must avoid the scheduling of any patient, only emergency dental cases are to be considered during the COVID -19 outbreak. But once the virus gets cleared off, to be more careful the following management shall be considered and followed to be on the safer side.

\section{Non-Emergency Complaints}

In cases of patients who don't require emergency treatments, they can be avoided to attend dental clinic, instead conversations can be done and instructions can be given by phone or text. And later a follow-up call will help maintaining the doctor - patient trust relationship. This gives patient a psychological relief and moral support too.

\section{What if Covid 19 Patient Requires Dental Treatment?}

Dental treatment to patients tested Covid 19 positive independently and without approval is strictly discouraged.
Such patients should be initially directed to the Government hospital or Covid 19 control centre, where they will be treated and provided necessary aid for their complaints. Any person without personal protective equipment should maintain a distance of $1-2$ meters and be in a well-ventilated area when dealing with Covid 19 patient.

In order to eliminate this, tele screening and triaging is helpful. Patients who seek dental appointments should be initially screened via telephone in order to identify suspected or possible Covid 19 infected person.

This can be done with 4 most relevant questions

1. Any exposure to a person with suspected or known Covid 19 patient?

2. Any recent travel history? (to check whether patient has gone to areas with high incidence of Covid 19)

3. Any respiratory illness, fever or cough?

4. Have you attended any meetings and gatherings recently?

Any positive response to these questions gives an alarm to the dental practitioner and can postpone the dental treatment and encourage the patient to self - isolate and immediately contact the health centre.

\section{Emergency Complaints}

Patients who require immediate treatment for their complaints should be considered "potentially infected" 26 and follow extra protective measures before communicating as well as treating the patients.

\section{Medical, Social and Travel History}

Firstly, a thorough history - taking should be done at all the dental visits. It must include the patient's medical history, a careful social history including information on recent changes in his work and living practices and travel history, keeping in mind of the current scenario. This should be done by sitting or standing, maintaining a certain distance while communicating with the patients. Medical history taking should include fever, cold, cough and respiratory problems other than the usual questionnaire. Social contacts and travelling spots should be noted if of any concern.

\section{Patient and Doctor Hand Hygiene}

The patient should be given hand sanitizer and instructed not to touch surfaces as well as face, eyes, nose and mouth. The dental practitioner also should make a habit of using hand sanitizer frequently as well as hand washing techniques lasting at least 20 seconds should be done, in order to reduce the spread of disease. Care must be taken to avoid touching their own eyes, mouth, and nose by the dental professionals. Minimum person entry should be allowed into the reception area and mainly the working area in order to avoid more exposure from other persons as well as to prevent them getting exposed to aerosols and water droplets near the working area. 


\section{PROTECTIVE MEASURES WHILE WORKING}

\section{Personal Protective Equipment}

Dental professionals should take all the extra protective measures considering the risk involved in treating patients. Based on the possibility of the spread of Covid 19, three-level protective measures for dental practitioners are recommended for specific situations ${ }^{5}$

1. Primary Protection(standard protection for dental staff in clinic) - Wearing disposable working head cap, disposable surgical mask, and working clothes (white apron), using protective eye wear or face shield, and disposable latex gloves or nitrile gloves.

2. Secondary Protection (advanced protection for dental practitioners) - Wearing disposable head cap, disposable surgical mask, protective eye wear, face shield, and working clothes with disposable isolation clothing or surgical clothes outside, and disposable latex gloves.

3. Tertiary Protection (strengthened protection) - If dental practitioner cannot avoid close contact with Covid 19 suspected or infected patient, special protective outwear is needed, i.e. Personal Protective Equipment.

Personal Protective Equipment consists of garments worn to protect the health care workers or any persons from getting infected. It includes face protection, goggles, mask / respirators / Filtering Face Piece, face shield, gloves, gown or coverall, head cover, rubber boots. In case if protective wear is unavailable, working clothes (white apron) with extra disposable protective clothing outside should be worn. In addition, disposable head cap, protective eye wear, face shield, disposable surgical mask, disposable latex gloves, and impermeable shoe cover should be worn. ${ }^{5}$

\section{Mouth Rinse, Rubber Dam Isolation, Use of Hand Piece}

Mouth rinses with antiseptic property are believed to reduce the viral load in the oral cavity. There is also a recommendation to use hydrogen peroxide or povidone iodine solutions. ${ }^{5,27,28,29}$ Hence, patient should be asked to rinse and gargle with beta dine mouth wash for a minimum of $30-40$ seconds before starting any clinical procedures. Patient should be asked to use mouthwash in between the treatment procedure also in order to reduce the viral load.

A study by Samaranayake et al has proved that the use of rubber dam significantly reduces airborne particles in 3 - foot diameter of the operational field by $70 \%{ }^{30}$ Hence the use of rubber dam helps in minimizing the contact with saliva and blood droplets when using high speed hand piece and ultra sonic scalars. Taking into consideration of this aspect, 4 handed technique is helpful for controlling infection as well as minimizes the time taken for treatment. The use of saliva ejectors with high or low volume will reduce aerosol and droplets to a large extent. In cases where rubber dam isolation is not possible, Carisolv for caries removal and hand scalar for scaling purpose can be a good option.

As high speed hand piece aspirates and expels debris and fluids during the clinical procedures, high speed hand piece with anti-retraction valves should be used in order to reduce cross infection. A study has shown that the anti - retraction high-speed dental hand piece significantly reduces the backflow of oral bacteria and viruses into the tubes of the hand piece and dental unit when compared with the hand piece without anti - retraction valve. ${ }^{31}$ Hence the use of hand piece with anti - retraction valve will be helpful in minimizing cross infection.

Extraoral Dental Suctions can also be used by dentists to safely remove droplets and aerosol particles that are produced during clinical procedures. These suctions are also capable in filtering the blood, viruses, germs, fluids, \& dust that would otherwise end up contaminating operatory, clothes, and body.

\section{Sterilization of Instruments and Surface Disinfection}

All the instruments must be autoclaved daily according to the number of patients and instruments needed. The reusable instruments must be cleaned, sterilized, and properly stored according to the Protocol for the Disinfection and Sterilization of Dental Instrument. All the surfaces should be cleaned and disinfected frequently, focusing on high touch surfaces like chairs, door handles etc. Wearing of disposable gloves when cleaning and disinfecting should be done. Protective eye wear as well as gowns or aprons should be worn by the attender cleaning and disinfecting surfaces in order to prevent the splash or splatter to the face and clothing.

After the completion of treatment, the dental chair should be cleaned using $1 \%$ sodium hypochlorite solution. The suction and spittoon should be drained using hypochlorite solution. Mopping of the floors using disinfectant solution is to be carried out daily. Fumigation of the clinic area and premises for disinfection should be done regularly. Air purifiers can be installed in the dental clinic in order to create fresh and safe inhaling air in the working environment.

\section{Organizing the Reception Area and Reception Staff}

Reception area is the first area of contact, hence modifications of certain aspects should be done like no appointment cards, no cash transactions, physical distancing from the people and patients coming for treatment and training and education of the clerical staff. Clerical staff should be asked to wear mouth mask. Waiting room should be organized with chairs arranged at a distance to each other. The waiting room should be well ventilated. All the magazines and products that can harbour virus should be removed. At the reception desk, the patient should be given hand sanitizer and instructed not to touch surfaces as well as face, eyes, nose and mouth. These instructions can be put on the notice board in the reception area and strictly asked to be followed by the patients and their accompaniers. Appointments should be minimized as well as minimal accompaniers should be allowed to accompany patients in the waiting room.

\section{Management of Clinic Waste}

The medical waste generated by the treatment of patients with suspected or confirmed Covid 19 infected patients are regarded as infectious medical waste, which need to be disposed properly. For this, double - layer yellow colour medical waste bags and "gooseneck" ligation must be used. 
The surface of the package bags should be marked and disposed carefully. ${ }^{5}$

\section{CONCLUSIONS}

Covid 19 has changed the face of the world bringing a lot of losses and disturbances in everyone's day-to-day life as well as professional life. Changes in the operating room as well as in the whole dental set up are for the protection of the dental practitioners and patients. Doing all treatment procedures with utmost care and self-protective measures can help us in running the dental care facility smoothly and more than that practice safely in this situation of increased risk because of Covid 19.

Financial or Other Competing Interests: None.

\section{REFERENCES}

[1] Ather A, Patel B, Ruparel NB, et al. Coronavirus Disease 19 (COVID-19): implications for clinical dental care. J Endod 2020;46(5):584-95.

[2] Centers for Disease Control and Prevention. Transmission of coronavirus disease 2019 (COVID-19). https://www.cdc.gov/coronavirus/2019ncov/about/transmission.html. Accessed 18 March, 2020.

[3] Sabino-Silva R, Jardim ACG, Siqueira WL. Coronavirus COVID-19 impacts to dentistry and potential salivary diagnosis. Clin Oral Invest 2020;24(4):1619-21.

[4] Darwish S. COVID- 19 considerations in Dental care. Dent Update 2020;47(4):287-302.

[5] Peng X, Xu X, Li Y, et al. Transmission routes of 2019-nCoV and controls in dental practice. International J Oral Sci 2020;12(1):9.

[6] Fehr AR, Perlman S. Coronaviruses: an overview of their replication and pathogenesis. Methods Mol Biol 2015;1282:1-23.

[7] Gorbalenya AE, Enjuanes L, Ziebuhr J, et al. Nidovirales: evolving the largest RNA virus genome. Virus Res 2006;117(1):17-37.

[8] Nakagawa K, Lokugamage KG, Makino S. Viral and cellular mRNA translation in coronavirus-infected cells. Chap- 5. In: Ziebuhr J, ed. Advances in Virus Research. Vol. 96. Elsevier 2016:165-92.

[9] Fan Y, Zhao K, Shi ZL, et al. Bat coronaviruses in China. Viruses 2019;11(3):210.

[10] Perlman S, Netland J. Coronaviruses post-SARS: update on replication and pathogenesis. Nat Rev Microbiol 2009;7(6):439-50.

[11] Weiss S, Leibowitz J. Coronavirus pathogenesis. Adv Virus Res 2011;81:85-164.

[12] Yin Y, Wunderink RG. MERS, SARS and other coronaviruses as causes of pneumonia. Respirology 2018;23(2):130-7.

[13] Zhou P, Yang XL, Wang XG, et al. A pneumonia outbreak associated with a new coronavirus of probable bat origin. Nature 2020;579(7798):270-3.

[14] Wahba L, Jain N, Fire AZ, et al. Identification of a pangolin niche for a 2019-nCoV-like coronavirus through an extensive meta-metagenomic search. https://www.biorxiv.org/content/10.1101/2020.02.08.9 39660v2.

[15] Rajput R, Chouhan Z, Suthar P, et al. MERS-CoV (Middle East Respiratory Syndrome Corona virus): a dental surgeon perspective. International Journal of Contemporary Medical Research 2015;2(5):1228-30.

[16] Li F. Structure, function, and evolution of coronavirus spike proteins. Annu Rev Virol 2016;3(1):237-61.

[17] Wu F, Zhao S, Yu B, et al. A new coronavirus associated with human respiratory disease in China. Nature 2020;579(7798):265-9.

[18] Giacomelli A, Pezzati L, Conti F, et al. Self-reported olfactory and taste disorders in patients with severe acute respiratory coronavirus 2 infection: a cross-sectional study. Clin Infect Dis 2020;71(15):889-90.

[19] Wu Z, McGoogan JM. Characteristics of and important lessons from the coronavirus disease 2019 (COVID-19) outbreak in China: summary of a report of 72314 cases from the Chinese Center for Disease Control and Prevention. JAMA 2020. https://doi.org/10.1001/jama.2020.2648

[20] Wei J, Li Y. Airborne spread of infectious agents in the indoor environment. Am J Infect Control 2016;44(9 Suppl):S102-8.

[21] To KKW, Tsang OTY, Yip CCY, et al. Consistent detection of 2019 novel coronavirus in saliva. Clin Infect Dis 2020;71(15):841-3.

[22] Ch T, Virk I, Bhavsar B, et al. Changing trends in dentistry: corona effect. Journal of Advanced Medical and Dental Sciences Research 2020;8(4):70-2.

[23] Rodriguez-Morales AJ, MacGregor K, Kanagarajah S, et al. Going global - travel and the 2019 novel coronavirus. Travel Med Infect Dis 2020;33:101578.

[24] Kampf G, Todt D, Pfaender S, et al. Persistence of coronaviruses on inanimate surfaces and their inactivation with biocidal agents. J Hosp Infect 2020;104(3):246-51.

[25] Otter JA, Donskey C, Yezli S, et al. Transmission of SARS and MERS coronaviruses and influenza virus in healthcare settings: the possible role of dry surface contamination. J Hosp Infect 2016;92(3):235-50.

[26] Spagnuolo G, De Vito D, Rengo S, et al. COVID-19 outbreak: an overview on dentistry. Int J Environ Res Public Health 2020;17(6):2094.

[27] Marui VC, Souto MLS, Rovai ES, et al. Efficacy of preprocedural mouthrinses in the reduction of microorganisms in aerosol: a systematic review. J Am Dent Assoc 2019;150(12):1015-26.e1.

[28] Kohn WG, Collins AS, Cleveland JL, et al. Guidelines for infection control in dental health-care settings -- 2003. MMWR Recomm Rep 2003;52(RR17):1-61.

[29] Zimmermann M, Nkenke E. Approaches to the management of patients in oral and maxillofacial surgery during COVID19 pandemic. J Craniomaxillofac Surg 2020;48(5):521-6.

[30] Samaranayake LP, Peiris M. Severe acute respiratory syndrome and dentistry: a retrospective view. J Am Dent Assoc 2004;135(9):1292-302.

[31] Hu T, Li G, Zuo Y, et al. Risk of hepatitis B virus transmission via dental handpieces and evaluation of an anti-suction device for prevention of transmission. Infect Control Hosp Epidemiol 2007;28(1):80-2. 